\title{
Fine needle aspiration cytology of rectal masses
}

\author{
R Kochhar, A Rajwanshi, J Dev Wig, N M Gupta, V Kesiezie, D K Bhasin, A K Malik, \\ S K Gupta, S K Mehta
}

\begin{abstract}
This paper describes the results of transproctoscopic fine needle aspiration cytology in the diagnosis of rectal lesions. Fifty one consecutive patients referred with a presumptive diagnosis of rectal mass were subjected to proctoscopic examination when fine needle aspiration cytology, brush cytology and biopsy samples were taken. Of the 30 patients of malignancy of rectum in whom all the three sampling techniques were applied, the biopsy was positive in $27(90 \%)$, brush cytology in 25 $(83.3 \%)$ and fine needle aspiration cytology in $29(96 \cdot 6 \%)$. A combination of fine needle aspiration cytology with brush cytology gave a positive yield in $96.6 \%$ while that fine needle aspiration cytology with brush cytology gave a yield of $100 \%$. Fine needle aspiration cytology was most helpful in infiltrative tumours. All 10 patients with secondaries in the pouch of Douglas or rectovesical pouch, and the single patient with submucosal rectal carcinoma were correctly diagnosed at fine needle aspiration cytology. There were no false positive results with fine needle aspiration cytology and no complications were encountered with the procedure.
\end{abstract}

Endoscopic biopsy and brush cytology are the two most common techniques for diagnosis of malignant lesions of the gastrointestinal tract. A number of workers have recently shown the usefulness of endoscopic fine needle aspiration cytology in achieving a better yield in certain types of malignancies. ${ }^{1-3}$ Using a bronchoscope the same technique has also been used for sampling paratracheal and subcarinal mass lesions. ${ }^{45}$ We have recently described the use of this technique for rectal masses using a proctoscope. ${ }^{6}$ This paper describes our experience in 51 patients subjected to transproctoscopic fine needle aspiration cytology.

Departments of

Gastroenterology,

Cytology, Pathology and

Surgery, Postgraduate

Institute of Medical

Education and Research,

Chandigarh, India

R Kochhar

A Rajwanshi

J Dev Wig

N M Gupta

$\checkmark$ Kesiezie

D K Bhasin

A K Malik

S K Gupta

S K Mehta

Correspondence to:

R Kochhar,

Dept Gastroenterology,

Postgraduate Institute of

Medical Education and

Research, Chandigarh 160012, India.

Accepted for publication 16 May 1989

\section{Methods}

\section{PATIENTS}

Fifty one consecutive patients (28 men, 23 women; age 27 to 67 years) with a presumptive diagnosis of a rectal mass were examined two to three hours after a rectal cleansing enema. A digital rectal examination was performed in a knee-chest position when the location and extent of the mass was noted as well as the condition of the mucosa. After adequate lubrication, a sterilised metal proctoscope was then introduced into the rectum, when the characteristics of the abnormality were confirmed. Submucosal masses were once again felt digitally through the proctoscope. Thereafter under direct vision the histol- ogy/cytology samples were taken from the target area in the following order: (i) fine needle aspiration using a $8 \mathrm{~cm}, 23$ gauge needle attached to a $20 \mathrm{ml}$ syringe, mounted on a suction handle (Cameco, Sweden) by the technique described earlier, ${ }^{6}$ (ii) brushing cytology using a cervical cytology brush (Medscan, Sweden), (iii) forceps biopsy using a standard punch biopsy forceps. In each patient two passes were made with the aspiration needle and two to four smears prepared. Brush cytology and biopsy samples were processed as per the standard practice. The cytology slides were air dried and stained with May-Grunwald-Giemsa stain. They were reported independently by two cytologists unaware of the histopathology report. Thirteen patients (metastases in the pouch of Douglas or rectovesical pouch (10); postradiation stricture (two); and submucosal rectal growth (one)) underwent fine needle aspiration cytology only, while all the three techniques were applied in 38 patients.

\section{Results}

The final diagnoses in 51 patients are given in Table I. Twenty eight patients had adenocarcinoma (Fig 1) and one patient each had

TABLE I Final diagnosis in 51 patients

\begin{tabular}{lr}
\hline \multicolumn{1}{c}{ Lesion } & $n$ \\
\hline 1 Malignancy of rectum (30) & 28 \\
(a) Adenocarcinoma & 1 \\
(b) Squamous cell carcinoma & 1 \\
(c) Malignant melanoma & \\
Metastatic deposits (pouch of Douglas or the rectovesical & \\
pouch) (10) & 5 \\
(a) Carcinoma of stomach & 1 \\
(b) Pancreatic carcinoma & \\
(c) Oesophageal carcinoma & 2 \\
Rectal polyp (4) & 2 \\
(a) Adenomatous polyp & 2 \\
(b) Juvenile polyp & 1 \\
5 Solitary rectal ulcer & 1 \\
6 Cast radiation stricture & \\
7 Tuberculosis of rectum & \\
\hline
\end{tabular}

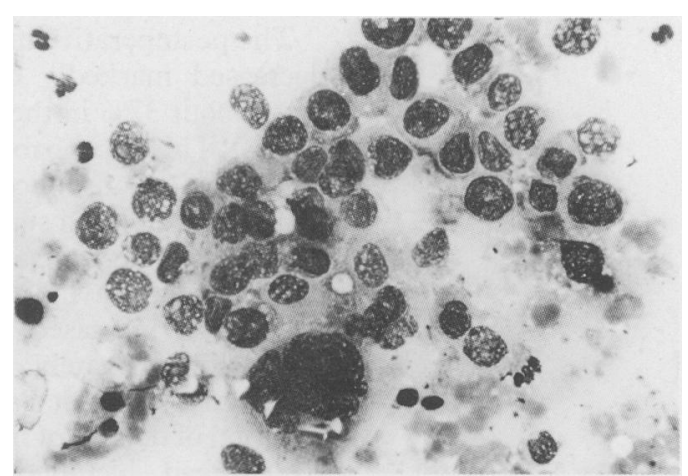

Figure 1: Fine needle aspiration smear showing clumps of cells in glandular pattern with prominent nucleoli and moderate amount of vacuolated cytoplasm; features of adenocarcinoma $(M G G)$. 


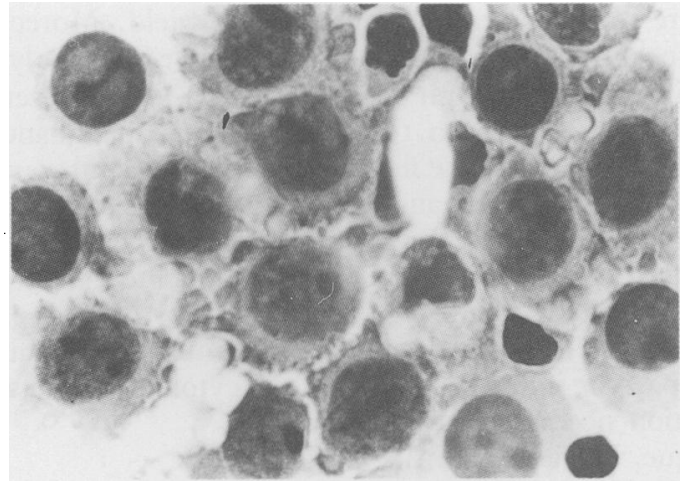

Figure 2: Fine needle aspiration smear of the patient with malignant melanoma. The smear shows discrete cell population with inclusion like nucleoli and pigmented cytoplasm $(P A P)$.

malignant melanoma (Fig 2) and squamous cell carcinoma (Fig 3) of the rectum. The carcinoma of rectum was polypoidal (18 patients), ulcerative (seven), infiltrative (three) or submucosal (one), while the solitary malignant melanoma was hard, nodular and greyish-black. Of the 41 patients proved to have a malignant lesion, 30 had been subjected to all the three techniques. In these patients the biopsy was positive in 27 , brush cytology in 25 and fine needle aspiration cytology in 29 patients. Table II gives the break up of patients with discordant reports. The sole false negative yield with fine needle aspiration cytology was in a patient with ulcerative growth. A combination of all the three techniques (Table III) gave a definitive diagnosis in all the 30 patients. There was no disparity between the histological and cytological diagnoses and there were no false positive results with any of the techniques.

Transproctoscopic fine needle aspiration cytology was positive for malignancy in all the 10 patients with deposits in the rectovesical pouch or the pouch of Douglas, and the aspirate showing features of adenocarcinoma. The origin of the primary tumour could not be detected in any of them. The metastatic deposits were clearly felt on digital examination and an irregular submucosal lesion was seen at proctoscopy in all

TABLE II Type of growth and results of different techniques in patients with discordant reports

\begin{tabular}{llll}
\hline Type of growth & Biopsy & Brush cytology & $\begin{array}{l}\text { Fine needle } \\
\text { aspiration } \\
\text { cytology }\end{array}$ \\
\hline Infiltrative & - & - & + \\
Infiltrative & - & - & + \\
Ulcerative & - & + & + \\
Ulcerative & + & - & + \\
Ulcerative & + & + & + \\
Polypoidal & + & - & + \\
Polypoidal & + & - & + \\
\hline
\end{tabular}

+ - positive/negative for malignancy.

TABLE III Diagnostic accuracy of combination of techniques in 30 patients

\begin{tabular}{llc}
\hline & Positive & $\%$ \\
\hline Biopsy+brush cytology & 28 & $93 \cdot 3$ \\
Brush cytology+FNAC & 29 & $96 \cdot 6$ \\
Biopsy+FNAC & 30 & 100 \\
Biopsy+brush +FNAC & 30 & 100
\end{tabular}

FNAC: Fine needle aspiration cytology.

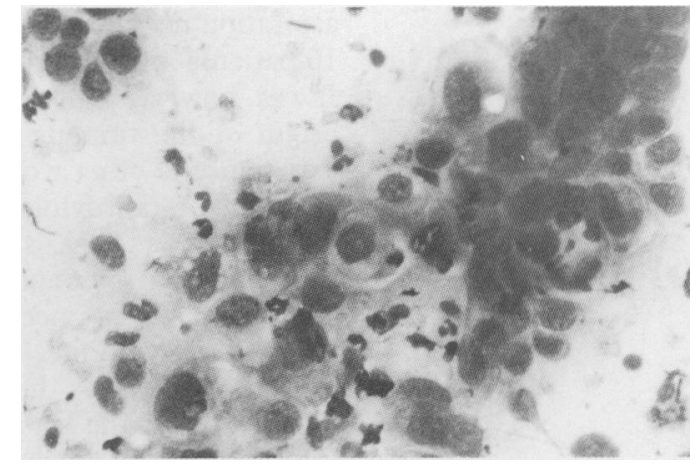

Figure 3: Fine needle aspiration smear showing squamous cell carcinoma $(M G G)$.

patients. In none of the 10 patients with a benign disease, any comment could be made about the nature of the lesion, at fine needle aspiration cytology or brush cytology.

\section{Discussion}

Fine needle aspiration cytology has been increasingly used in the last two decades as a simple, safe and quick method to achieve morphological diagnosis. An adaptation of fine needle aspiration cytology has been used by endoscopy for the diagnosis of bronchopulmonary ${ }^{4}$ and oesophagogastric ${ }^{1-3}$ malignancies. It has been felt that endoscopic fine needle aspiration cytology has a higher sensitivity compared with other techniques as it can sample infiltrative and submucosal tumours more successfully. ${ }^{356}$ Our results are in accordance with these observations. The positive yield $(96.6 \%)$ with transproctoscopic fine needle aspiration cytology was higher than with brush cytology $(83.3 \%)$ or biopsy $(90 \%)$ in our patients. Combining the results of fine needle aspiration cytology and biopsy could establish the diagnosis in all the 30 patients with a malignancy involving the rectum (Table III). A combination of biopsy and brush cytology had a negative yield in two (67\%) of the patients.

False negative results with endoscopic biopsy may be caused by infiltrative tumours, ${ }^{78}$ ulcerative tumours covered with necrotic debris, ${ }^{78}$ and submucosal growths. ${ }^{9}$ Brush cytology can increase the diagnostic yield in infiltrative tumours and obstructing lesions that prevent the passage of the endoscope to the desired site. ${ }^{10}$ Submucosal tumours and growths covered with necrotic material, however, still pose a diagnostic problem. Proctoscopic fine needle aspiration cytology is likely to have a better sensitivity in infiltrative and submucosal tumours and may sample the fungating growths better. The number of patients with infiltrative and ulcerative growths was quite small in the present study but all three infiltrative tumours were correctly diagnosed at fine needle aspiration cytology. The single patient with submucosal tumour of the rectum had a hard, nodular growth correctly diagnosed by fine needle aspiration cytology.

This study shows the usefulness of fine needle aspiration cytology for metastatic deposits in the pouch of Douglas or the rectovesical pouch Hitherto such lesions were difficult to sample. At proctoscopy these deposits can be visualised directly and palpated as well, thus guiding the 
aspiration needle. We were successful in all the 10 patients in whom the technique was applied. It was, however, not possible to comment on the origin of the tumour. This has also been the experience of other workers who have done fine needle aspiration cytology of intrapelvic organs. " These workers have sampled the suspect area through the transvaginal or transrectal route using Franzen's needle. When using the Franzen's technique, originally described for prostatic tumours, ${ }^{12}$ the tip of the index finger is used to guide the aspiration needle. With the transproctoscopic technique, however, the suspect area is both seen and felt and the needle insertion into the tissues is made under direct vision.

The role of fine needle aspiration cytology in benign lesions lies primarily in excluding malignancy. Solitary rectal ulcer is known to be confused with a malignant process. ${ }^{13} \mathrm{~A}$ combination of biopsy, brushing and fine needle aspiration cytology can exclude the latter possibility to a reasonable extent as was our experience. Tuberculosis of the rectum, though rare, can also pose a diagnostic problem. In the solitary patient with ulcerohyperplastic tubercular lesion of the rectum, the biopsy showed epithelioid granulomas with caseation while both the cytological techniques (brushing and fine needle aspiration cytology) had shown only benign columnar cells. The negative yield with fine needle aspiration cytology was in all probability because of inadequate sampling.

There are certain limitations of the use of fine needle aspiration cytology. First, this technique cannot be used for typing benign lesions. Second, the fine needle aspiration cytology report of no evidence of malignancy has to be seen in the total context of the patient. The false negative yield of fine needle aspiration cytology of different organs in the body ranges from $1 \cdot 8 \%$ to $10 \% .14-17$ Thus a negative aspirate does not necessarily rule out the possibility of a malignancy. Third, the application of the technique of fine needle aspiration cytology in polypoid lesions leaves much to be desired. Though fine needle aspiration cytology correctly diagnosed the absence of malignancy in all four of our patients, this technique may be inadequate in such lesions. If the stalk alone harbours a malignant focus, the aspiration needle may not reach that area and fine needle aspiration cytology will get a false negative yield. Moreover, the malignant cells aspirated from a polyp may represent only a carcinoma in situ. Even otherwise also, reliable diagnosis of malignancy in polypoid lesions in colorectum requires architectural evidence of invasion which can be seen only in solid polypectomy or biopsy specimens. ${ }^{18}$

We conclude that proctoscopic fine needle aspiration cytology is extremely useful in sampling submucosal and infiltrating tumours, while brush cytology has an adjunctive role in stenotic lesions.

1 Kochhar R, Gupta SK, Malik AK, Mehta SK. Endoscopic fine needle aspiration biopsy. Acta Cytol 1987; 31: 481-4.

2 Lange P, Kock K, Laustsen J, Arffmann E, Teglbjaerg PS Endoscopic fine needle aspiration cytology of the stomach. A new diagnostic procedure. Endoscopy 1987; 19: 72-3.

3 Iishi $H$, Yamamoto R, Tatsuta M, Okuda S. Evaluation of fine needle aspiration biopsy under direct vision gastrofiberscopy in diagnosis of diffusely infiltrative carcinoma of the stomach. Cancer 1986; 57: 1365-9.

4 Laundgreen R. A flexible thin needle for transbronchia aspiration biopsy through the flexible fiberoptic bronchoscope. Endoscopy 1980; 12: 180-2.

5 Wang KP, Terry PB. Transbronchial needle aspiration in the diagnosis and staging of bronchogenic carcinoma. Am Rev Resp Dis 1983; 127: 344-7.

6 Kochhar R, Rajwanshi A, Bhasin DK, Mehta SK. Fine needle aspiration cytology of rectal tumors - Technical note. Dis Colon Rectum 1988; 31: 655-6.

7 Qizilbash AH, Castelli M, Kowalski MA, Churly A. Endoscopic brush cytology and biopsy in the diagnosis of cancer scopic brush cytology and biopsy in the diagnosis of cance of the

8 Kochhar R, Rajwanshi A, Malik AK, Gupta SK, Mehta SK. Endoscopic fine needle aspiration biopsy of gastroesophageal malignancies. Gastrointest Endosc 1988; 34: 321-3.

9 Tabilian N, Smith JL, Schwartz JT, McHenry MM, Graham DY. Endoscopic needle biopsy of gastrointestinal lesion [Abstract]. Gastrointest Endosc 1986; 32: 175.

10 Kobayashi S, Kasugai T. Brushing cytology for the diagnosis of gastric cancer involving the cardia or the lower esophagus. Acta Cytol 1970; 22: 155-7.

11 Kjellgren $\mathrm{O}$, Angstrom T. Transvaginal and transrectal aspiration biopsy in diagnosis and classification of ovarian tumours. In: Zajicek J, ed. Aspiration biopsy cytology, Part 2: cytology of infradiaphragmatic organs. Basel: S Karger, 1979: 80 of in 103 .

12 Franzen S, Giertz G, Zajicek J. Cytological diagnosis of prostatic tumours by transrectal aspiration biopsy: a pre iminary report. Brf Urol 1960 32: 193-6.

13 Kochhar R, Malik AK, Nanda V, Singh K, Mehta SK. Clinical spectrum of solitary rectal ulcer. Indian $\mathcal{F}$ Gastroenterol 1987; 6: 31-3.

14 Zajicek J. The aspiration biopsy smear. In: Koss LG, ed. Diagnostic cytology and its histopathologic bases. 3rd ed. Philadelphia: J B Lippincott, 1979: 1001-104.

15 Schneider KL, Schreiber K, Silver CE. The initial evaluation of masses of the neck by needle aspiration biopsy. Surg Gynecol Obstet 1984; 159: 450-2.

16 Brauer RJ, Silver CE. Needle aspiration biopsy of thyroid nodules. Laryngoscope 1984; 94: 38-42.

17 Silver CE, Koss LG, Brauer RJ, et al. Needle aspiration cytology of tumours at various body sites. Curr Probl Surg cytology of tum

18 Mortensen NJ, Eltringham WK, Mountford RA, et al. Direct vision brush cytology with colonoscopy: an aid to the accurate diagnosis of colonic strictures. BrF Surg 1984; 71 930-2. 